\title{
ANALYSIS OF BULBOUS BOW RESISTANCE WITH DIMPLE (BASIN) ON KRI CLASS STRATEGIC SEALIFT VESSEL (SSV) USING CFD SOFTWARE
}

\author{
Dwi Putra Maulana, Irfan Syarif Arief, Cahya Kusuma, \\ Wawan Kusdiana, Mohammad Syaifi \\ Indonesian Naval Technology College, STTAL \\ Bumimoro-Morokrembangan, Surabaya 60187, Indonesia
}

\begin{abstract}
The function and role of the Strategic Sealift Vessel (SSV) ship type is very important. Modifications and changes to improve the value of efficiency will be very necessary. This efficiency value is closely related to the value of Ship Resistance, where if the Resistance value goes down, the value of the ship's efficiency will rise. The increase in efficiency is then expected to reduce fuel consumption and increase speed. In several studies, ways have been improved to improve the condition, one of them is by adding a Dimple to the Surface Area of the ship, this modification will reduce the friction Resistance that the ship will receive by reducing the Wetted Surface Area that the fluid will pass at certain speeds and conditions. . This modification will be applied to the ship's Bulbous Bow section. In this way it is expected to improve the value of the Resistance produced by the Bulbous Bow installed in the ship, without having to carry out significant changes or modifications and change the shipbuilding of the existing Linesplane. Furthermore, the analysis is carried out by modeling using $2 D$ and 3D CAD Software and Model Experiments using CFD Applications. After carrying out the entire process of Running with the CFD Software to determine the value of the Ship Resistance. The final conclusion is in the form a reduction the value of vessel Total Resistance the Running Bow section of $31.53 \%$ in the 4th variations and Fn used is 0,341 .
\end{abstract}

Keywords: Boulbous Bow, CFD, Dimple, Reduction, Resistance .

\section{INTRODUCTION}

\subsection{Back Ground}

Strategic Sealift Vessel or Type of Vesselwhat we call SSV is an innovation shipand engineering from previous Ship production, namely Landing Platform Dock or LPD which is technology transfer with Korea.Two units of LPD vessels produced were approved and owned and operated, namely KRI Banjarmasin - 592 and KRI Banda Aceh - 593, these two ships entered the Operational range Military Naval Command or Kolinlamil and already widely used in Military Operationsand humanity at the International level and have recognized ability. Reviewing the Role of KRI Class SSV highly urgent, so that need implemented improvements improvements and researchin order to increase the level of efficiency of the ship. So Ship operations can be better going forward. This efficiency is closely related to Speed and Use of Fuel. To get it increase in ship efficiency, there are a number of things that are we can concentrate on addition speed or reduction in material consumption burn, that is we have to reduce things toan element of Resistance, for example Resistance waves, \& friction resistance, which is formed because of the speed of the ship and its hydrodynamics related to ship building. In this research, it will be conducted development from previous research by applying dimple to Bulbous Bow on SSV type vessels. This matter intended to provide nilat benefits which is more than the existing Bulbous Bow. So Existing and dimple bows can reduce Resistance greater than the standard Bulbous Bow which is formed according to the KRI Lines Plane Banjarmasin or SSV Class Ship. As well as on Final Bulbous Bow Total Resistance value this modification can be better or smaller compared to Conventional Bow. 


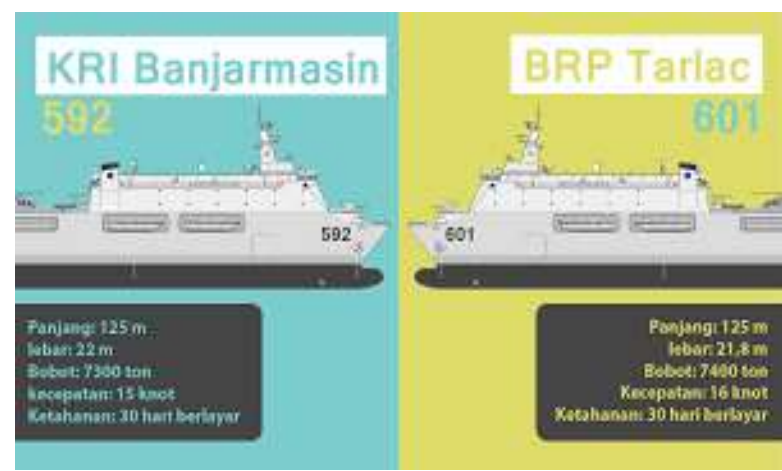

Fig.1 Comparison of KRI Banjarmasin and BRP Tarlac

(source: netz.id/news)

Process processing data Analysis using a software approach. Formaking ship models using CAD software3D Maxsurf Modeller. And use model analysis get the total resistance value using Numeca Fine Marine CFD Software

\subsection{Problem Formulation}

Problems to be solved in this research is :

a. How the application affects dimple on the Bulbous Bow against ResistanceTotal ship ?

b. How does change ratio affect Diameter to Side of the Square (RDS) and Change in Concentration Ratio (RC) to Resistance of the ship ?

c. How does the Resistance change in value before and after the addition of dimple?

\subsection{Research Purpose}

In this research program was formulated the following objectives:

a. Knowing the effect is added dimple to the value of the ship's custody.

b. Knowing the smallest Total Resistance Value from dimple variations.

c. Know the value of Resistance before and after adding dimple.

\subsection{Research Benefits.}

a. With this modification is expectedbe a solution in terms of reduction of Resistanceship, without having to make a changelarge and Displacement and $\mathrm{Cb}$ remain appropriate with the existing Lines Plan. b. As input for the Navy withinrepair / modification of KRI Class Bulbous BowSSV / LPD

\section{Literature Review}

\subsection{Ship Resistance}

The ship's resistance is force needed to maintain the occurrence of these waves when a body ship moving or speeding on the area surfaces that are free of fluid, by because of that the amount of pressure on the surrounding area the hull will produce waves influid surface.

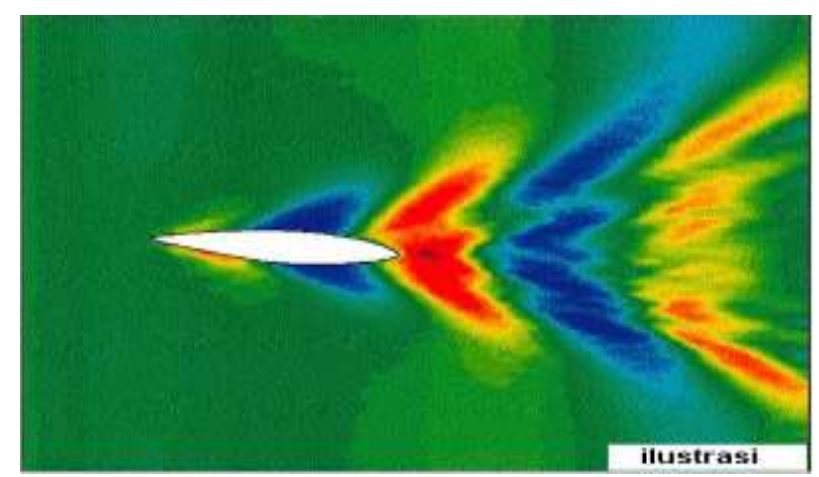

Fig.2 Bow Wave System

In this case the occurrence of tangential forcesthe opposite direction with the direction of body movementvessels caused by viscosity factorsfluid and hull motion. Based onthe two Resistance were knownWave making Resistance and Viscous or alsoknown as Frictional Resistance.

\subsubsection{Friction Resistance}

Friction resistant is a Resistance that occurs as a result ofthe body of a ship through which fluid flowshas viscosiatas (Viscous) for example water the sea. Fluid flows in opposite directions with the direction of motion of the ship to cause friction on the surface of the hull this is what called the frictional resistance (Sv.Aa. Harvald,1992) 


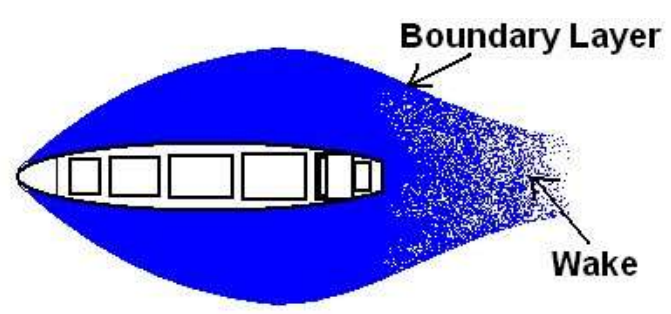

FRICTIONAL RESISTANCE

Fig.3 Frictional Resistance

\subsubsection{Wave Resistance}

Wave resistance is a Resistance arising from the movement of ships with the surface of the water, giving rise to agood waves when water is staticor dynamic, waves consist of:

a. Radiating Waves iemoving waves radiating stay away from the ship, which is streaks wave crests leaning in the direction behind to wards the ship's center line.

b. Transverse waves that is the wave that goes in the direction stern of the ship, and peak lines waves perpendicular to the center line ship.
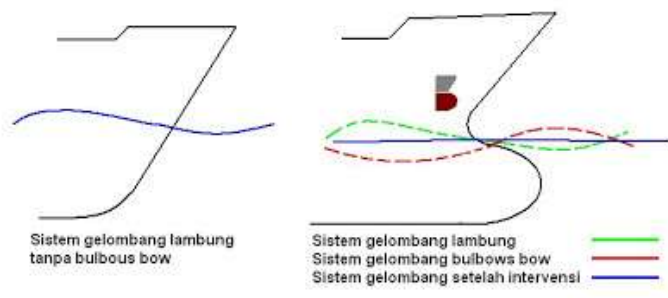

Fig.4 Wave Resistance

\subsection{Fluid Flow}

\subsubsection{Laminar}

Laminer is the fluid flow shown with the motion of the fluid particles parallel and the current lines are smooth. In flow laminer, fluid particles as if move along smooth trajectories and smooth, with one layer gliding in a manner smooth on adjacent layers. Nature the viscosity of liquid plays an important role in flow formation laminer. Flow laminar steady meaning the flow is fixed. Shows that in the entire flow of water, discharge steady flow or no flow speed change according to time.

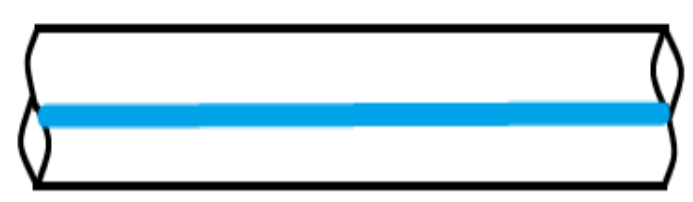

Fig.5 Laminar Flow

\subsubsection{Transition}

Transition Transition flow is a form of transitional flow from laminar flow to turbulent flow. Transitional that occurs from laminar flow and turbulent flow because it is above the Reynolds Figures in particular, laminar flow becomes unstable, if a small disturbance is given to the flow, then the influence of this flow becomes even greater with increasing time. A flow will said to be stable when disturbances muted. It can be concluded that below Reynolds figures for which certain pipe flows are laminar will be stable for each disorder the small one.

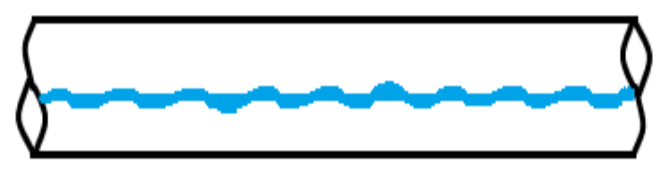

Fig.6 Transition Flow.

\subsubsection{Turbulent}

Flow velocity with a relative value large will produce a flow that does not laminar but a complex condition, the trajectory of particle motion that occurs will be mutual irregular between one another. So that you will get the characteristics of flow turbulent : the absence of order that occurs inin its fluid trajectory, a lot of flowmixed, high fluid velocity, scale lengthlarge flow and low viscosity. The characteristics of turbulent flow are shown by vortex formation - vortex in the flow, which results in continuous mixing between fluid particles through out flow cross section. As per the definition of Flow Transition then turbulent flow occurs if a number Reynolds owned are greater than 4000 (> 4000). 


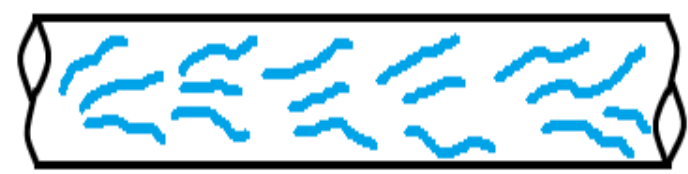

Fig.7 Turbulent Flow

Flow To distinguish whether turbulent flowor laminer, there is an unified number called Reynold Numbers (Reynolds Number). This number is calculated by the equation as the following:

$\mathrm{Re}=(4 \vee \mathrm{R}) / \vartheta$

Where :

$$
\begin{aligned}
& \mathrm{Re} \quad=\text { Reynold Number (without unit) } \\
& \mathrm{V} \quad=\text { Average Speed (ft/s or m/s) } \\
& \mathrm{R} \quad=\text { Hydraulic Radius ( } \mathrm{ft} \text { atau } \mathrm{m} \text { ) } \\
& \vartheta \quad=\text { Kinematics Viscosity, available } \\
& \text { intable of fluid properties (ft2 / } \mathrm{s} \text { or } \mathrm{m} 2 / \mathrm{s} \text { ) }
\end{aligned}
$$

\subsection{Bulbous Bow}

ulbous Bow is a form of bow which has an ovoid shape which placed at the height of the front of the bow. The use of this bulbous bow will have an effectin the flow of water around the ship's hull. An explanation of the effects of the occurrence of water flow around the ship ie water is forced to flow onover the Bulbous Bow so that it will break down waves of water that hold in front of him (Harahap, 2018).

The theory underlying the system Bulbous Bow usage is application from the Bernoully principle. From the results of the research shows a change in speed and fluid pressure. For example a fluid passes throughan object $A$ for example when fluid flowswith velocity $\mathrm{V} 0$ and then PO pressure until the boundary Layer A - A occurs deflection. It turns out that the speed of $P 1$ willget bigger due to surface constriction liquid on the side of object $A$. Then this is according to principle bernoully with the increasing value of $\mathrm{P} 1$ it will be followed by a decrease in value of V1 (Adi, 2013)

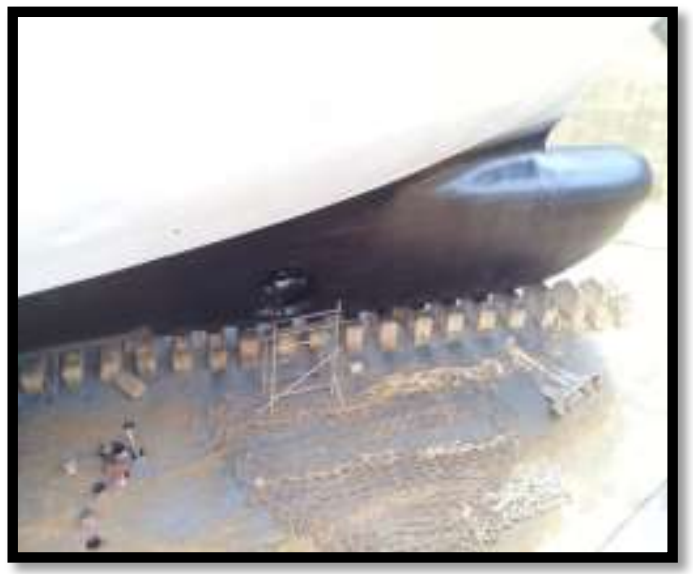

Fig.8 Bulbous Bow KRI Banjarmasin - 592 .

The principle of work of the first Bulbous Bow it was introduced by a European researcher named Lord Kelvin and Willian Froud are introduced to19 th century after researching the owned Bow wave by battleships with conditions certain. Bulbous Bow can reduceship barriers by minimizing WSA (Wet Surface Area) so that it can eventually reduce fuel consumption $12-15 \%$. In addition to reducing WSA, Bulbous Bow also has a function distribute wave pressure to along the ship, this is called a form effect which in essence will be able to decreasewave resistance value

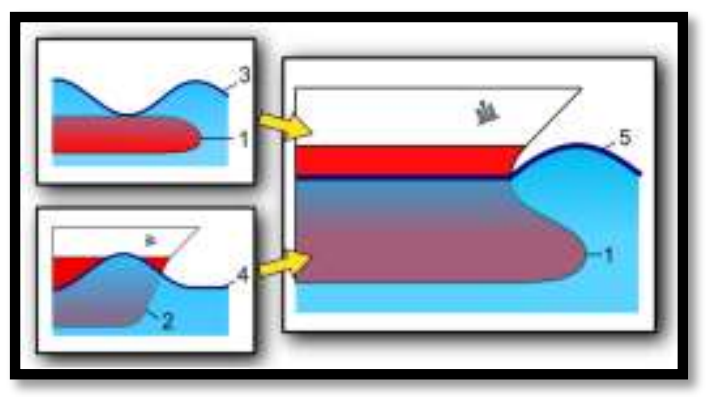

Fig.9 Figure of Wave Movement Inaround the hull due to the Boulbous Bow (Source: mar.ist.utl.pt/mventura)

The shape of the bulbous bow plays a role important in determining the magnitude of benefits which is given. The very optimum form depends on the size of the Froude number. Bulbous bow tends to give performance which is good when the ship moves beyond the limit certain speed in the sense that the ship is moving with a relatively high speed. 
Froude number it self is a function of speed ship which in detail is shown that the speed of the ship is directly proportional to the value this number, so when the ship has Froude numbers are large then level the bulb's optimization will be greater for the shape the same, but the value of Fn isn't just determined by the speed of the ship but also by lengthship. So it is true that the design the shape of the bulbous bow is determined by Fn.

One way to see the effect of the function of the bulbous bow is its Resistance by using the equivalent power length instead see from Lpp or $L w l$. Where as for determine the effective installation on Bulbous Bow is determined by Fn, $0.29<\mathrm{Fn}$ $<0.32$. (Schneekluth, 1998).

Things that must be considered in Bulbous Bow design is into accountship obstacles and find out efficiency the use of a bulbous bow on a ship. Make Linggi bow shape with bulb will more expensive than making tall shapes ordinary bow, so the bulb is only selected if it is indeed can reduce obstacles, to determine The size of the Bulbous Bow is based on several the intermediate factor gives the formula equation with the following approach:

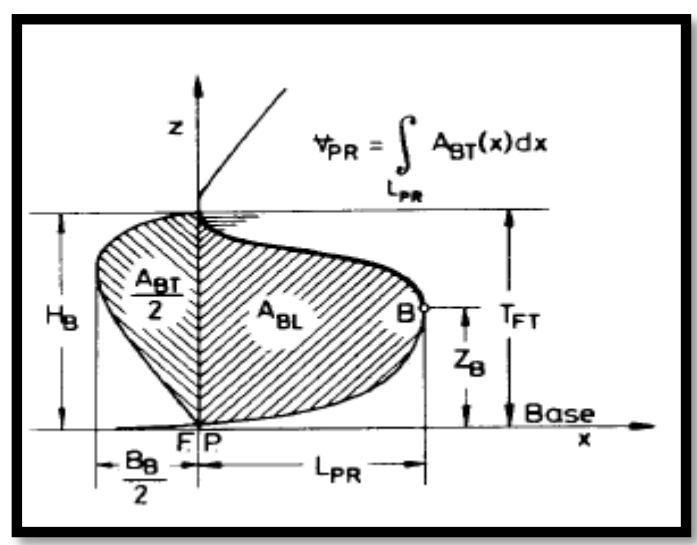

Fig.10 Coefficient of non-linear and Linear

\subsection{Dimple}

The ball used in the sport of golf has a special shape and configuration, namely the surface which has dimple - small dimple, This shape apparently has influence on the aerodynamics of golf balls the. The golf ball is made with holesmake shifting layers in the air slower because there is a small layer on ball grooves on the surface such that extend the sliding distance of the air layer onthe closest layer to the surface, so air velocity on the surface rises so that different speed with a layer above it more small that it can also reduce the incidence turbulence at the end of the ball.

\subsection{Computational Fluid Dynamic (CFD)}

Computational Fluid Dynamic or CFD is a system analysis that involves flowfluid, heat transfer, and phenomena that are related to others such as chemical reactions with using computer simulations. This method covering phenomena related tofluid flow like a two-phase liquid system, mass and heat transfer, chemical reactions, gas dispersion or movement of suspended particles. In general, the CFD framework includes formulation of transport equations which areapplies, the formulation of appropriate boundary conditions, selection or development of codes computing to implement techniques numeric used. A CFD code consists from three main elements namely pre-processor, solver and post processor.

As for some of the advantages obtained by using CFDs including :

a. Minimize time and costsin designing a product, if it is a process. The design is done by test experiments with high accuracy.

b. Having the ability of the study system who can control the experiment which is difficult or impossible in experimentation.

c. Having the ability to study in under dangerous conditions when or after passing a tipping point (including studies safety and accident scenario)

d. Its accuracy will always be controlled in the design process. 


\section{Research Methodology}

3.1 Research Flowchart

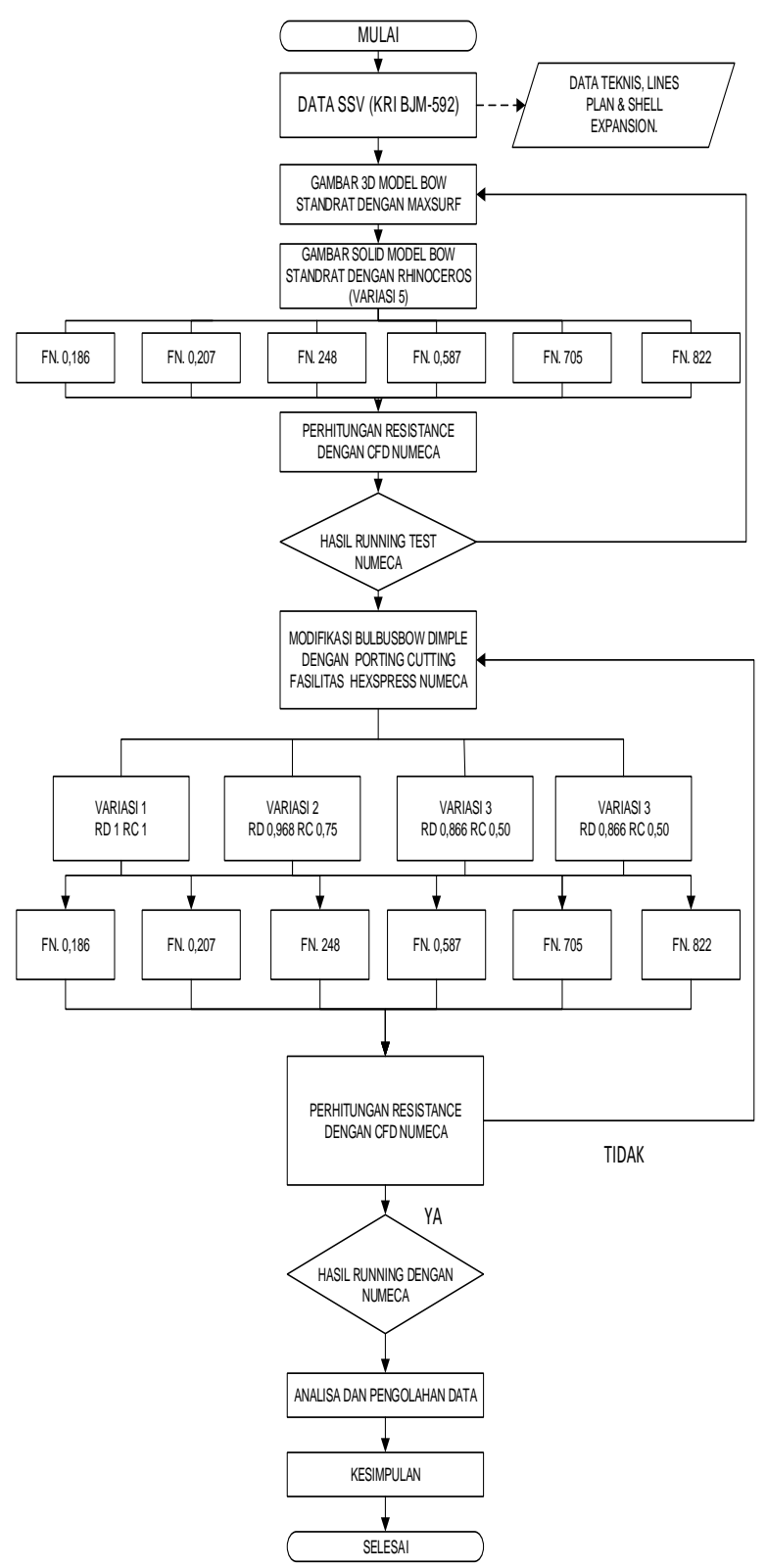

Fig.11 Flow Chart

\section{Analysis and Discussion}

\subsection{Initial Data}

Primary data of ship dimensions KRI Banjarmasin 592 Strategic Sealift Vesseal Types ( SSV ) by using a Bulbous Bow (BowConventional) as follows :

$\begin{array}{ll}\text { Displacement } & : 7.300 \text { Tons } \\ \text { Length over all } & : 122,00 \text { meter } \\ \text { Length of water line } & : 112,2 \text { meter }\end{array}$

$\begin{array}{llll}\text { LPP } & : 109,2 \text { meter } \\ \text { Depth } & : 11,30 \text { meter } \\ \text { Draft } & : \quad 5,00 \text { meter } \\ \mathrm{Cb} & : \quad 0,58 & \\ \mathrm{Cp} & : & 0,62 & \\ \mathrm{Cm} & : & 0,94 & \\ \text { Wetted Area } & : 2578,196 \quad \mathrm{~m}^{2}\end{array}$

Bulbous Bow data in this study, as illustrated in Figure 12 comes from Data Lines Plan in general or whole bodyship and cut through the Maxsurf Software Modeller. The Bulbous Bow data on This research is as follows :

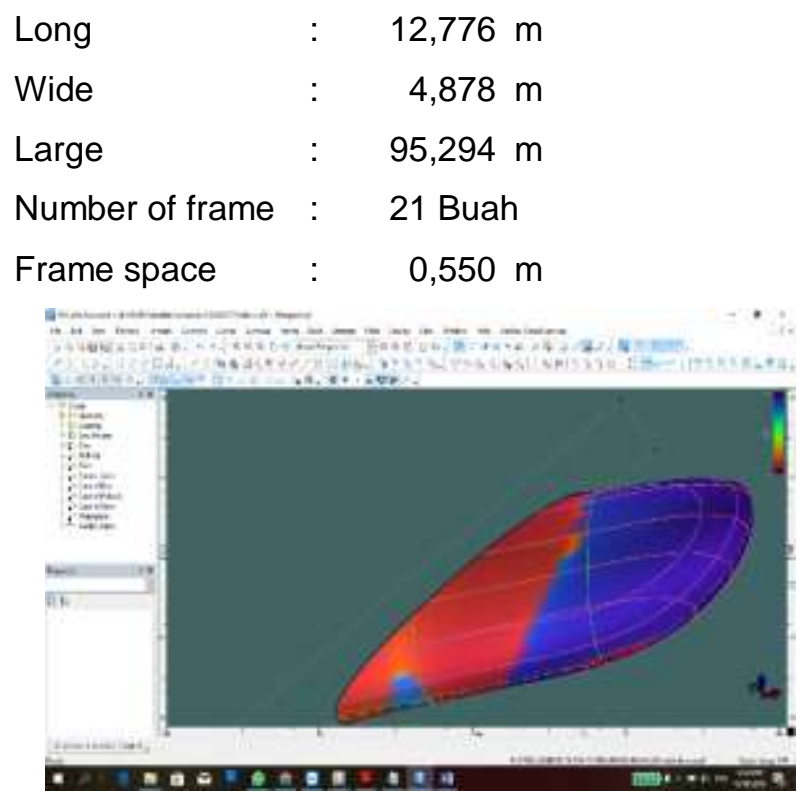

Fig.12 Pieces of KRI Bulbous BowBanjarmasin 592 by usingMaxsurf Modeller Software

\subsection{Data and Design Parameters}

The previous sections have been explainedthat the variations carried out in this analysisis in the ratio of dimple to longitude diametercage and concave ratio.

The main data neededfor the modeling and simulation processthis experiment is planned as follows:
a. Long model
: $15,000 \mathrm{~m}$
b. LWL
: $7,823 \mathrm{~m}$
c. Wide model
: $18,977 \mathrm{~m}$
d. Hight model
: $15,195 \mathrm{~m}$ 

e. Draft
: $5,000 \mathrm{~m}$
f. WSA
$: 153,59 \mathrm{~m}$
g. Bow Large
: $95,294 \mathrm{~m}^{2}$
h. RC Variation
$: 1 ; 0,75 ; 0,50 ; 0,25 ; 0$
i. RD Variation
$: 1 ; 0,968 ; 0,866 ; 0,661 ; 0$
j. Froude Number : 0,$186 ; 0,217 ; 0,248 ; 0,310$
; $\quad 0,434 ; 0,587 ; 0,705 ; 0,822$.

Table 1. Research Variations

\begin{tabular}{|c|c|c|c|c|c|c|c|c|c|c|c|}
\hline$\infty$ & $\begin{array}{l}\text { Sisilipin } \\
\text { Sayoze }\end{array}$ & 205 & $x$ & $\begin{array}{c}\text { Danter } \\
\text { int }\end{array}$ & Kedaman & \multicolumn{6}{|c|}{ Fodel hunter } \\
\hline Va. 1 & 550 & 1 & 1 & 0275 & 0275 & 1,155 & 0288 & 0.341 & 1587 & 0,705 & 1.202 \\
\hline Va. 2 & 550 & 1958 & 1,75 & 0256 & 1265 & 1,155 & 0288 & 0.341 & 1,587 & 0,705 & 1.02 \\
\hline Vx. 3 & 550 & 1086 & 150 & 0228 & 1,135 & 1,155 & 0,28 & 0.341 & 1,507 & 0,705 & 1,022 \\
\hline Va. 4 & 550 & 1.651 & 125 & 0,182 & 1,664 & 1,155 & 0288 & 0.341 & 1,587 & 0,765 & 182 \\
\hline Va. 5 & Reta & 0 & 0 & 0 & 1 & 1,155 & 0288 & 0.341 & 1587 & 0,705 & 10202 \\
\hline
\end{tabular}

\subsection{Analysis Results}

Data tabulated in the form table in the previous section, then meshand running into the Numeca Fine CFD Software Marine can be graphed Total Resistance Value (Rt). This running process requires a lot of time differ between Variants. So it is with graphics obtained has a time lag (Time Lapse) different between variants to achieve run speed.

Furthermore, the graph data obtained from the running process of the CFD program will be tabulated return to detail the difference in value got

\subsubsection{CFD Numeca Fine Marine Running Results} Graph.

a. Variation 1 Fn. 0,$587 ; 0,705 ; 0,822$

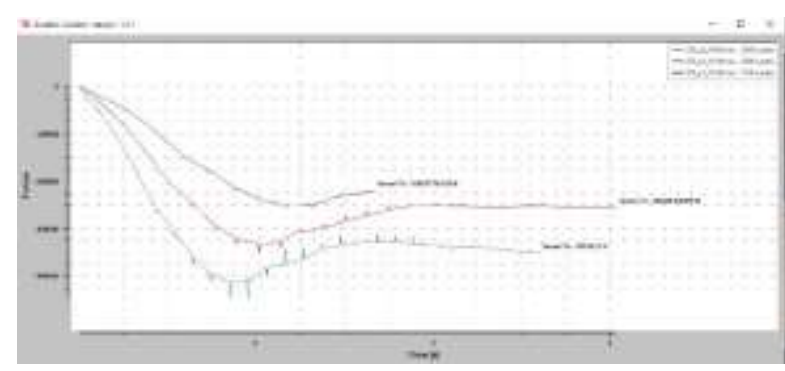

Fig.13 Total Resistance Graph Variation 1 b. Variation 2 Fn. 0,$587 ; 0,705 ; 0,822$

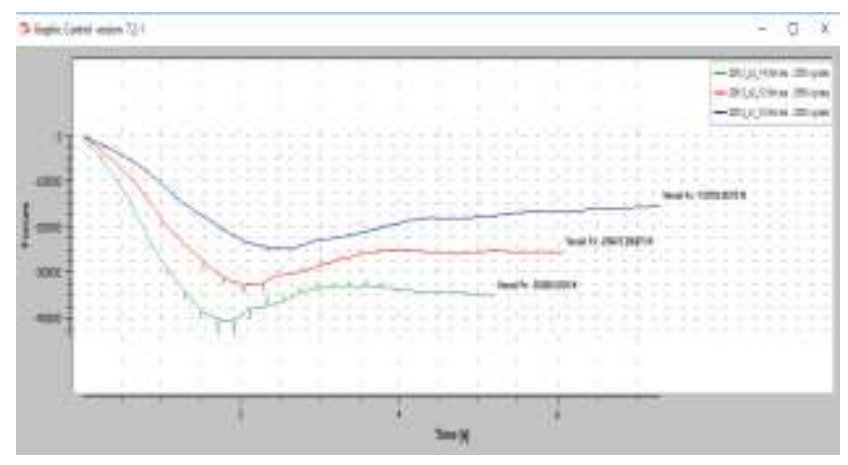

Fig.14 Total Resistance Graph Variation 2

c. Variation 3 Fn. 0,$587 ; 0,705 ; 0,822$

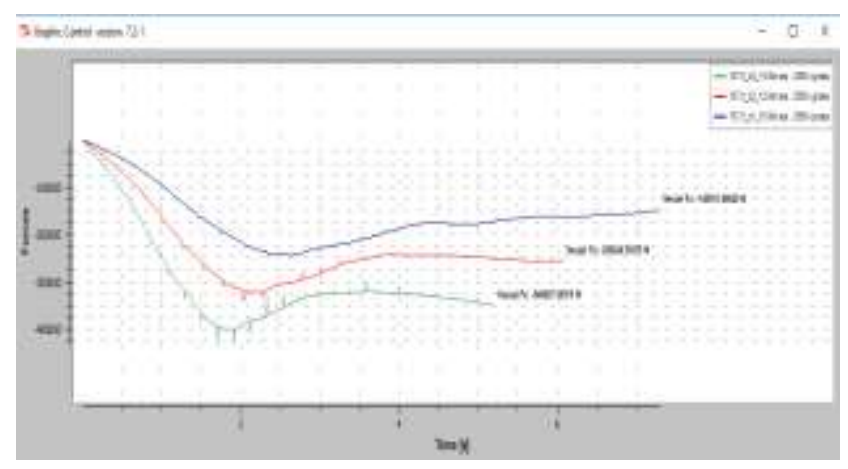

Fig.15 Total Resistance Graph Variation 3

d. Variation 4 Fn. 0,$587 ; 0,705 ; 0,822$

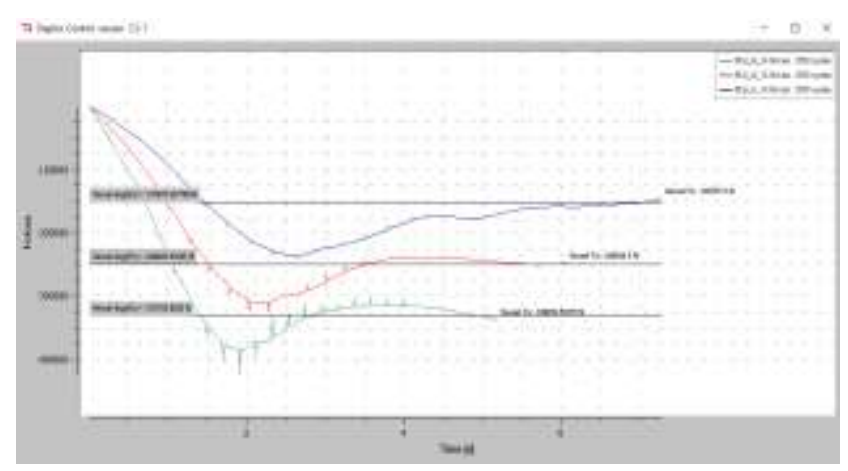

Fig.16 Total Resistance Graph Variation 4

e. Variation 5 Fn. 0,$587 ; 0,705 ; 0,822$

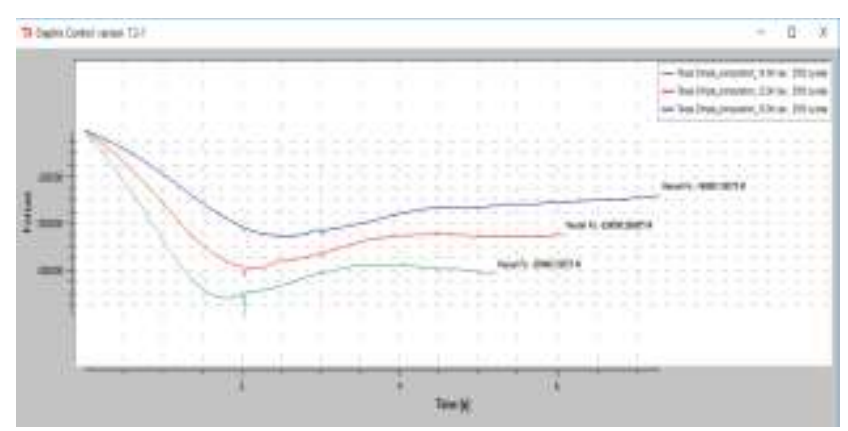

Fig.17 Total Resistance Graph Variation 5 
f. Variation 1 Fn. 0,$155 ; 0,248 ; 0,341$.

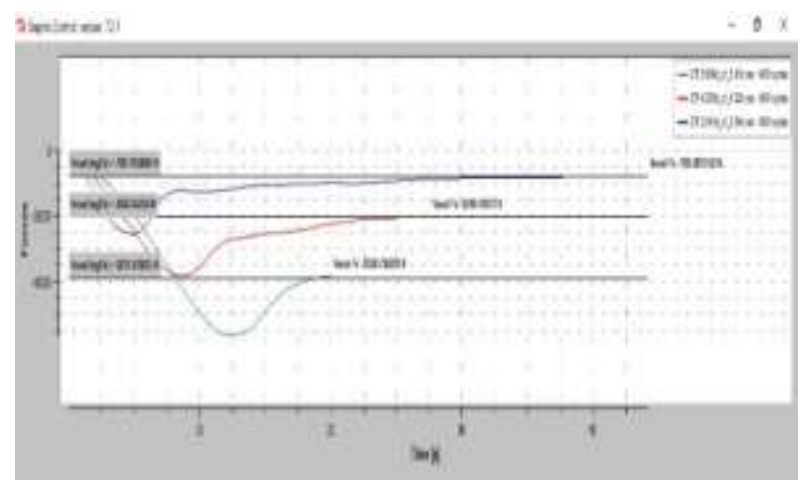

Fig.18 Total Resistance Graph Variation 1

g. Variation 2 Fn. 0,$155 ; 0,248 ; 0,341$.

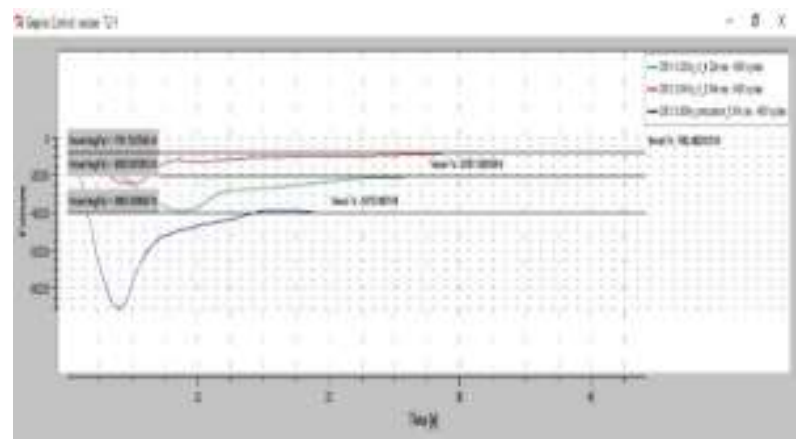

Fig.19 Total Resistance Graph Variation 2

h. Variation 3 Fn. 0,$155 ; 0,248 ; 0,341$

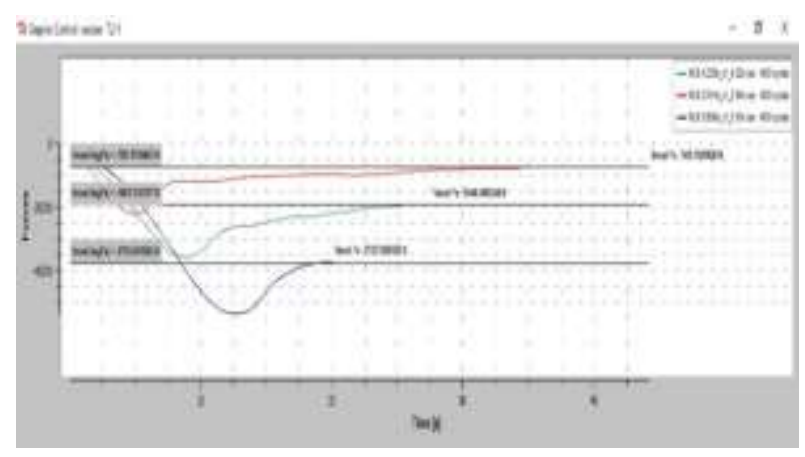

Fig.20 Total Resistance Graph Variation 3

i. Variation 4 Fn. 0,$155 ; 0,248 ; 0,341$

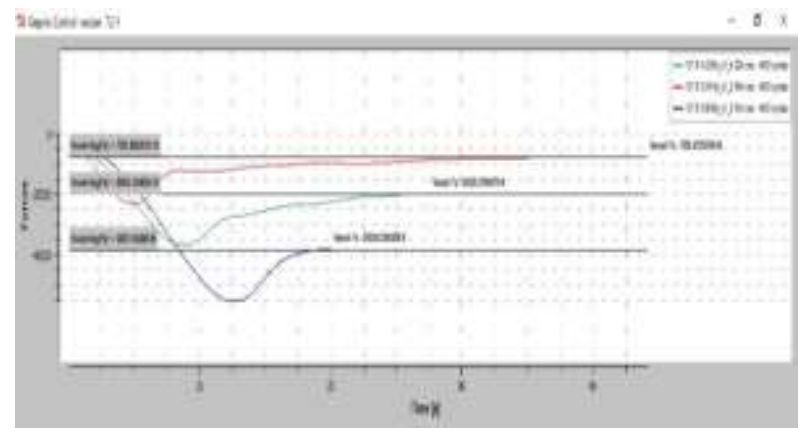

Fig.21 Total Resistance Graph Variation 4 j. Variation 5 Fn. 0,$155 ; 0,248 ; 0,341$.

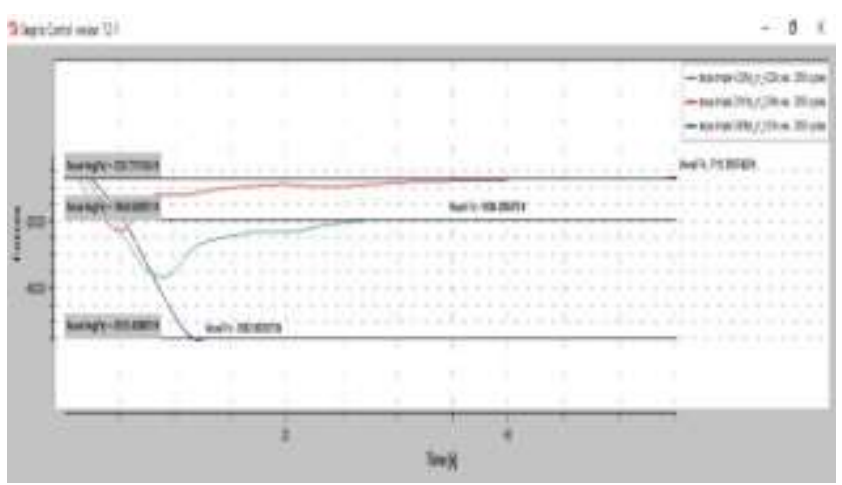

Fig.22 Total Resistance Graph Variation 5

\subsubsection{Table of Running Results Graph CFD Numeca Fine Marine Table.}

Table 2. Resistance of Running Variation 1

\begin{tabular}{|c|c|c|c|c|c|}
\hline \multicolumn{5}{|l|}{ Variasi 1} & \multirow[b]{2}{*}{ Differences } \\
\hline & $F_{n}$ & $V_{S_{\text {nasus }}(k+1)}$ & $\mathrm{Rn}$ & Rt(Newton) & \\
\hline 10 & 0,155 & 2,638 & 10960231 & 7559,207031 & 04,41 \\
\hline 16 & 0,248 & 4,221 & 17536369 & 20069,109375 & 02,13 \\
\hline 22 & 0,341 & 5,804 & 24112505 & 38326,738281 & $-30,51$ \\
\hline 37 & 0,587 & 9,838 & 40871053 & 219027,703125 & 55,55 \\
\hline 45 & 0,705 & 11,999 & 49851370 & 254698,296875 & 13,40 \\
\hline 52 & 0,822 & 13,990 & 58124576 & 351390,500000 & 13,37 \\
\hline
\end{tabular}

Table 3. Resistance of Running Variation 2

\begin{tabular}{|c|c|c|c|c|c|}
\hline \multicolumn{5}{|l|}{ Variasi2 } & \multirow[b]{2}{*}{\begin{tabular}{|l|} 
Differences \\
\end{tabular}} \\
\hline$V_{s_{\text {s.wu }}(k t)}$ & $F_{n}$ & $V_{S_{\text {nasus }}(k+1)}$ & $\mathrm{Rn}$ & Rt(Newton) & \\
\hline 10 & 0,155 & 1,629 & 2476569 & 7700,000000 & 06,35 \\
\hline 16 & 0,248 & 4,221 & 17536369 & 20590,000000 & 04,78 \\
\hline 22 & 0,341 & 5,804 & 24112505 & 39680,000000 & $-28,05$ \\
\hline 37 & 0,587 & 9,838 & 40871053 & 153789,093750 & 09,22 \\
\hline 45 & 0,705 & 11,999 & 49851370 & 256473,296875 & 14,19 \\
\hline 52 & 0,822 & 13,990 & 58124576 & 352563,812500 & 13,75 \\
\hline
\end{tabular}

Table 4. Resistance of Running Variation 3

\begin{tabular}{|c|c|c|c|c|c|}
\hline \multicolumn{5}{|l|}{ Variasi 3} & \multirow[b]{2}{*}{ Differences } \\
\hline$V_{S_{\text {s.w }},(k t)}$ & $F_{n}$ & $V_{s_{\text {manst }}(k t)}$ & $\mathrm{Rn}$ & Rit(Nenton)] & \\
\hline 10 & 0,155 & 1,629 & 2476569 & 7560,0000000 & 04,42 \\
\hline 16 & 0,248 & 4,221 & 17536369 & 20050,000000 & 02,04 \\
\hline 22 & 0,341 & 5,804 & 24112505 & 38360,000000 & $-30,44$ \\
\hline 37 & 0,587 & 9.838 & 40871053 & 148701,906250 & 05,61 \\
\hline 45 & 0,705 & 11,999 & 49851370 & 256024,593750 & 13,99 \\
\hline 52 & 0,822 & 13,990 & 58124576 & 349827,593750 & 12,87 \\
\hline
\end{tabular}

${ }^{*}$ viskositas air laut $1,883 \times 10^{-8} \mathrm{~m}^{2} / \mathrm{s}$ 
Table 5. Resistance of Running Variation 4

\begin{tabular}{|c|c|c|c|c|c|}
\hline \multicolumn{5}{|l|}{ Variasi 4} & \\
\hline$V_{5 \text {-ax }}(k t)$ & $F n$ & $V_{5}$. noste $(k t)$ & $\mathrm{Rn}$ & Rt (Newton) & Difference \\
\hline 10 & 0,155 & 1,629 & 2476569 & 7390,000000 & 02,07 \\
\hline 12 & 0,186 & 3,166 & 13152276 & 10730,000000 & 00,56 \\
\hline 14 & 0,217 & 3,693 & 15344322 & 14950,000000 & 00,40 \\
\hline 16 & 0,248 & 4,221 & 17536369 & 19480,000000 & $-00,87$ \\
\hline 22 & 0,341 & 5,804 & 24112505 & 37760,000000 & $-31,53$ \\
\hline 37 & 0,587 & 9,838 & 40871053 & 145797,500000 & 03,55 \\
\hline 45 & 0,705 & 11,999 & 49851370 & 248549,500000 & 10,66 \\
\hline 52 & 0,822 & 13,990 & 58124576 & 338052,593750 & 09,09 \\
\hline
\end{tabular}

Table 6. Resistance of Running Variation 5

\begin{tabular}{|c|c|c|c|c|c|}
\hline \multicolumn{5}{|l|}{ Variasi 5} & \multirow[b]{2}{*}{ Difference } \\
\hline$V_{5}$-and $(k t)$ & Fn & $V_{s_{\text {. nosto }}(\mathrm{kt})}$ & $\mathrm{Rn}$ & Rt(Newton) & \\
\hline 10 & 0,155 & 1,629 & 2476569 & 7240,000000 & 00,00 \\
\hline 12 & 0,186 & 3,166 & 13152276 & 10670,000000 & 00,00 \\
\hline 14 & 0,217 & 3,693 & 15344322 & 14890,000000 & 00,00 \\
\hline 16 & 0,248 & 4,221 & 17536369 & 19650,000000 & 00,00 \\
\hline 22 & 0,341 & 5,804 & 24112505 & 55150,000000 & 00,00 \\
\hline 37 & 0,587 & 9,838 & 40871053 & 140801,593750 & 00,00 \\
\hline 45 & 0,705 & 11,999 & 49851370 & 224598,296875 & 00,00 \\
\hline 52 & 0,822 & 13,990 & 58124576 & 309945,593750 & 00,00 \\
\hline
\end{tabular}

\subsubsection{Graph Comparison of all models}

The graphic below illustrates about the comparison of the resistivity values of all the models in which the $Y$ axis side of the graph contains resistance values, and $X$ axis of the graph contains Froude Number.

a. Comparison Chart Var. 1 and Var. 5.

$$
\mathrm{Ft}-\mathrm{Fn}
$$

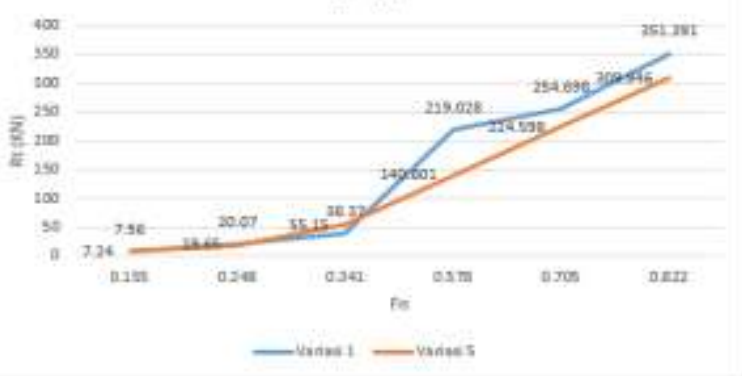

Fig.23 Comparison Graph Rt - Fn Variation 1 and 5

b. Comparison Chart Var. 2 and Var. 5.

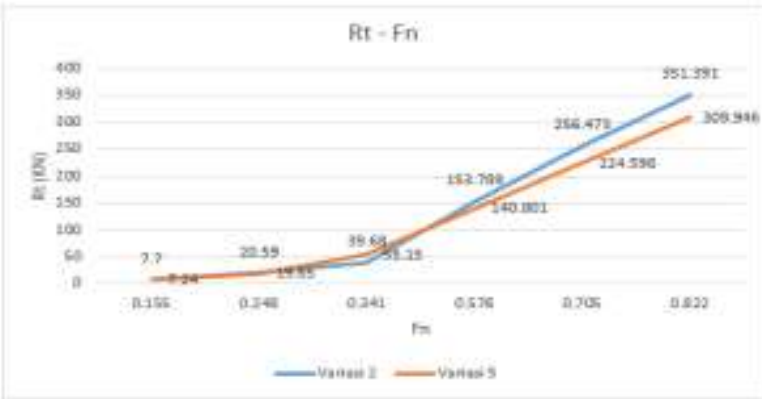

Fig.24 Comparison Graph Rt - Fn Variation 2 and 5

c. Comparison Chart Var. 3 and Var. 5.
Rt - Fn

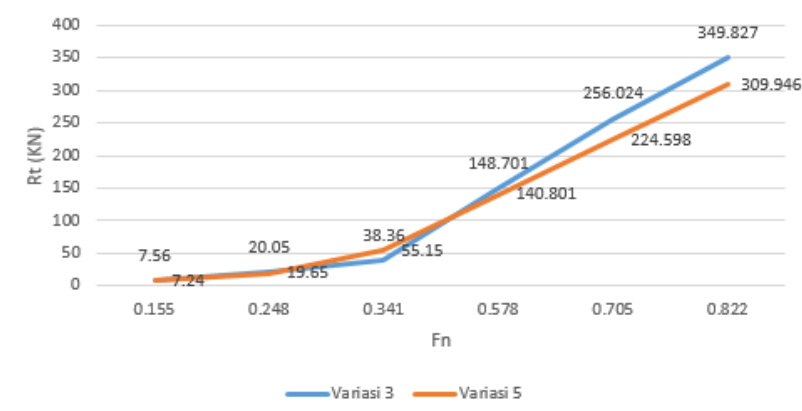

Fig.25 Comparison Graph Rt $-F n$ Variation 3 and 5

d. Comparison Chart Var. 4 and Var. 5.

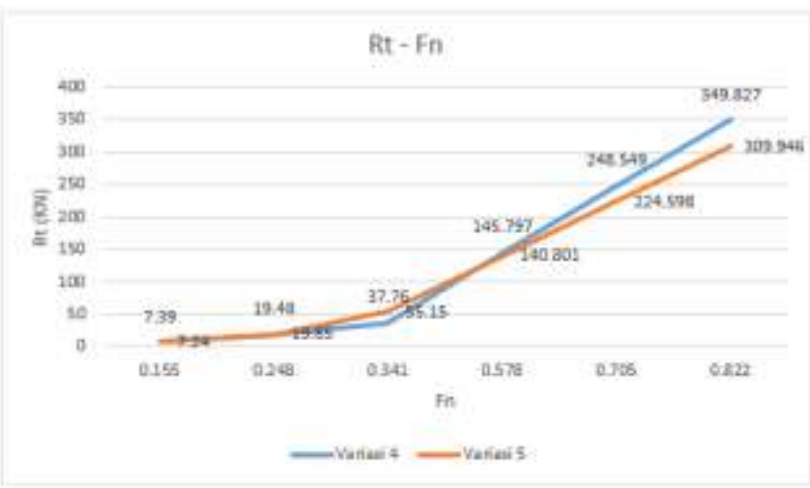

Fig.26 Comparison Graph Rt - Fn Variation 4 dan 5

e. Comparison Chart all Variation.

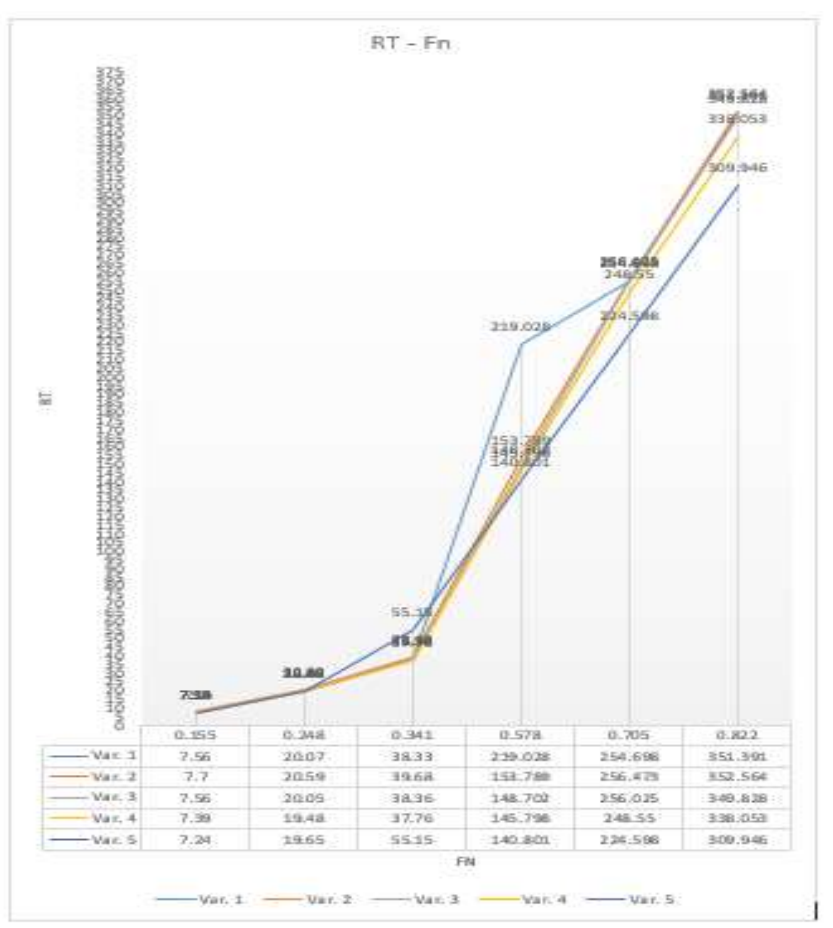

Fig.27 Comparison Graph Rt - Fn all Variable. 


\section{CONCLUSIONS AND SUGGESTIONS}

\subsection{Conclusions}

From the results of testing and analysis of models with research variations of Bulbous Bow flat surface (without Dimple) and Bulbous Bow Dimple variations, then conclusions can be drawn the following:

a. On Froude Number (Fn) between 0.2480,341 modifications in the form of enhancers Dimple on Surface Area can reduce the total Resistance value $(\mathrm{Rt})$ of the ship.

b. Rt value the smallest is in variation 4 with RDS 0.661 and RC 0.25 or Dimple diameter 0.182 m and depth Dimple 0.0688 m, at Fn 0,341 Variation 4 can reduce resistance by $31.53 \%$

c. Change in the value of Rt. very influenced by the use of Fn. during the simulas process, where in Fn . smaller than 0.248 all over Rt. Bulbous bow modification stends to be greater than Rt. Bow conventional standard without Dimple. But at Fn . 0.248 - 0.341 modifications can bereduce Rt. up to $31.53 \%$ or of $18.00 \mathrm{KN}$. Next on Fn .0,341 - 0,822 the value of Total Resistance at the entire variation of Boulbus Bow results greater modification compared Conventional standard Bulbous Bow without modification with an increase of $5-50 \mathrm{KN}$ or $2.00-13.50 \%$. So it can be noted that modification by applying Dimple toThe surface of the ship must pay attention to the value of $\mathrm{Fn}$. which is used both in the simulation processas well as on ship shipping operationsin fact.

\subsection{Sugesstion}

From the results of testing and analysis of Bulbous Bow flat surface with Bulbous Bow with this Dimple, the author gives some suggestions as follows:

a. It is hoped this research canfurther developed withgive Dimple on all parts ships under water, and carried out analysis on the entire body of the ship. b. From the simulation results CFD Numeca order can continue the real simulation on the ship existing models to obtain value which is approaching real.

c. As already stated in Conclusions above, the application of Dimple must really pay attention to the value of $\mathrm{Fn}$. used in the simulation processas well as on ship shipping operationsin fact.

\section{REFERENCES}

Adjie, R. W. et al. 2017. Development of Experiments for the Effect of Basin (Dimple) Applied to Flat Plates Against Fluid Flow.

Almujahidin, M. A. et al. 2012. Experiments on the Effect of Deposits Applied to Flat Plates Against Fluid Flow. Experiments on the Effect of Deposits Applied to Flat Plates Against Fluid Flow.

Coal, R. R. et al. 2014. Experiments on the Influence of Dimple (Basin) Delivery on MV Nurul IImi's Hull.

Diputra, R. 2014.. KRI Banda Aceh-593 Help Search AirAsia QZ 8501

Firmanullah, D. M. et al. 2014. Utilization of Dimple Technology on Ship Hulls to Reduce Ship Prisoners. Utilization of Dimple Technology on the Hull of the Ship to Reduce the Resistance of the Ship., 1-5.

Kurniawan Nizar, P. et al. 2013. Analysis of the effect of the basin applied to the flat plate on fluid flow to support the maritime technology approach of the CFD.

Mohammad, W. 2011. Cargo Ship. Retrieved from Blogger website: http://kapalcargo.blogspot.com/2011/04/tain-pada-kapallaut.html?m=1

Putra, A. 2015. Operation to free the crew of the MV Sinar Kudus. Retrieved from Wikipedia website:

https://id. wikipedia.org/w/index.php?title=Oper asi_pembliberation_awak_kapal_MV_Sinar_K udus\&oldid $=95044 \overline{5} 6$

Rivai, A. 2011. Ship Speed. Retrieved July 10, 2019, from Blogspot website: http://antonrivai.blogspot.com/2011/12/keccel-kapal.html 
Santoso, A. I. et al. 2013. Flow and Pressure Analysis in Bulbous Bow with Dimple Using the CFD Approach.
Setyawan, Dwi A. 2018. Analysis of the Effect of Bulbous Bow Installation on Strategic Sealift Vessel (SSV) Type Ship Performance Using Maxsurf and Marin DSPPC Software. 